\title{
V. Toxikologie.
}

\section{Vergiftung mit Fliegenwasser.}

Der $2 \frac{1}{8}$ Jahr alte Sohn einer Frau auf dem Lande trank, als seine Mutter auf kurze Zeit das Zimmer verlassen hatte, aus einem Töpfchen, welches auf dem Tische stand, und Fliegenwasser enthielt, das seine Mutter von einer Freundin zum Geschenk erhalten hatte.

Obwohl sich alsbald heftige Anzeichen der Vergiftung einstellten, wurde dennoch bis zum folgenden Tage gezögert, zu welcher Zeit die Mutter mit dem. Kinde nach der Stadt kam, und den hiesigen Arzt Dr. F. consultirte.

Dieser, die Symptome der Arsenik-Vergiftung erkennend, verordnete alsbald Ferrum hydricum in aqua, leider ohne Erfolg, da das Gift bereits zu lange gewirkt hatte.

Am folgenden Morgen, am 1. August c., verschied der Knabe.

Ein ungefährliches Fliegenwasser wird durch eine Abkochung von Quassia-Holz und langem Pfeffer erhalten.

Namentlich wird von der Abkochung des langen Pfeffers gerühmt, dass die Fliegen todt bleiben, während sie nach dem Gennsse der Quassia-Abkochung aus ihrer Betäubung wieder erwachen sollen.

Festenberg, den 10. August 1868.

L. Hoffmann. 